\title{
Percepção materna sobre transtornos psiquiátricos no puerpério: implicações na relação mãe-filho
}

\author{
Maternal perception about postpartum psychiatric disorders: implications in mother-child relationship
}

Percepción materna sobre trastornos psiquiátricos en el puerperio: implicaciones en la relación madre-hijo

\author{
Elaine Cristina Carvalho Moura', Marcia Astrês Fernandes", Flayda Isabela Rodrigues Apolinário"I' \\ ' Universidade Federal do Piauí. Curso de Graduação em Enfermagem. Teresina-PI, Brasil. \\ "Universidade Federal do Piauí. Curso de Graduação em Enfermagem. Hospital Areolino de Abreu. Teresina-PI, Brasil. \\ III Faculdade NOVAFAPI. Teresina-PI, Brasil.
}

Submissão: 16/06/2009 Revisão: 26/01/2011 Aprovação: 21/02/2011

\section{RESUMO}

Objetivou-se analisar as implicações dos transtornos psiquiátricos na relação mãe-filho na percepção da mulher em puerpério. Utilizou-se abordagem qualitativa descritiva com dados colhidos em entrevista semiestruturada aplicada a dez puerperas, selecionadas pelo diagnóstico de transtorno psíquico no puerpério. Os dados coletados foram discutidos pela técnica de análise de conteúdo. Os resultados apontam dificuldades das pacientes em se perceber doentes, devido a fatores culturais e sociais que agem frente aos fatores biológicos na definição de diagnóstico e tratamento dos transtornos, havendo prejuízo no prognóstico, acarretando danos na relação mãe-filho. Concluiu-se que, apesar da incidência e gravidade dos transtornos psiquiátricos no ciclo gestacional, os serviços e profissionais de saúde precisam ser provocados na efetivação de ações preventivas para minimizar o sofrimento psíquico a mulheres acometidas.

Descritores: Percepção; Mulheres; Transtornos Puerperais; Transtornos Mentais.

\section{ABSTRACT}

That is a descriptive qualitative research that aimed to analyze the implications of the psychiatric disorders in the mother-child relationship, according to the maternal perception. Data were collected though semi-structured interview with ten women, selected by the diagnosis of mental disorders in the postpartum period. The collected data were discussed through the content analysis technique. The results pointed difficulties of the mothers to feel themselves sick, due to cultural and social factors that act in the presence of biological factors in the definition of the diagnosis and treatment of the disorders; determining impairment in the prognosis and, causing damages in the mother-child relationship. One concluded that, although the incidence and gravity of psychiatric disorders in the gestational cycle, the professionals and health services still need to be provoked for the implementation of preventive actions to minimize the psychic suffering of the women affected.

Key words: Perception; Women; Puerperal Disorders; Mental disorders.

\section{RESUMEN}

Se objetivó analizar implicaciones de trastornos psiquiátricos en la relación madre-hijo, en la percepción de la mujer puérpera. Se utilizó enfoque cualitativo descriptivo con datos recogidos por entrevista semiestructurada en diez madres diagnosticadas con trastorno psíquico en puerperio. Los datos recogidos fueran discutidos por la técnica de analice de contenido. Los resultados muestran dificultades de las pacientes en percibirse enfermas, debido a factores culturales y sociales que ajen frente a los biológicos en la definición de diagnóstico y tratamiento de trastornos, habiendo prejuicio en el pronóstico, y trayendo danos para la relación madre-hijo. Se concluye que, aunque exista incidencia y gravitad de trastornos psiquiátricos en el posparto, los servicios y profesionales de salud precisan ser provocados para la efectuación de acciones preventivas, que disminuyan el sufrimiento de las mujeres acometidas.

Palabras clave: Percepción; Mujeres; Trastornos Puerperales; Trastornos Mentales. 


\section{INTRODUÇÃO}

A evolução da psiquiatria clínica tem demonstrado que as fases do ciclo reprodutivo envolvem elementos potencialmente estressores, indicando vulnerabilidade para transtornos mentais, tendo como fatores atuantes as alterações neuroquímicas e hormonais, associadas a agravos menstruais, alterações de personalidade, predisposição biológica, bastante característicos desse momento do ciclo de vida da mulher e mais evidentes após o parto ${ }^{(1)}$.

No puerpério ocorrem reações conscientes e inconscientes na mulher envolvendo o seu ambiente familiar e social, ativando ansiedades. Uma das mais importantes é a vivência inconsciente da angústia do trauma do próprio nascimento. Ao longo dos nove meses de gestação o filho é parte integrante e inerente da mulher que, no momento do parto, vive uma grande perda. O nascimento do filho gera a diferenciação(2).

Esse significado do parto pode trazer uma situação de transtorno à puérpera: o parto representa vida e também morte. Os transtornos psiquiátricos mais comuns são: disforia do pós-parto, síndrome da tristeza Pós-Parto e psicose puerperal ${ }^{(3)}$

A disforia no pós-parto inclui sintomas depressivos leves e pode ser identificada em $50 \%$ a $85 \%$ das puérperas, dependendo dos critérios diagnósticos utilizados ${ }^{(4)}$. A Síndrome da Tristeza Pós-Parto, ou depressão pós-parto, é um distúrbio emocional comum, podendo ser considerada uma reação esperada no período pós-parto imediato e que geralmente ocorre na primeira semana depois do nascimento da criança. Entre 50 a $80 \%$ de todas as mulheres apresentarão reações emocionais $^{(3)}$.

Diversos fatores influenciam a precipitação de transtornos associados ao puerpério, sendo importante destacar os biológicos e psicológicos, bem como a associação destes com o meio cultural e social da mulher. Os biológicos resultam da variação nos níveis de hormônios sexuais circulantes e de uma alteração no metabolismo das catecolaminas, causando alteração no humor e podendo contribuir para a instalação do quadro depressivo. Os psicológicos se originam de sentimentos conflituosos da mulher em relação a si mesma, como mãe; ao bebê; ao companheiro; ou a si mesma, como filha da sua própria mãe ${ }^{(4)}$.

A percepção da mãe é um aspecto importante no diagnóstico indício para um bom prognóstico em psiquiatria, considerando que uma mãe que tem consciência do seu estado mental adere mais facilmente ao tratamento proposto tendo assim um resultado mais rápido e eficaz. Isso resulta em uma melhora significativa no relacionamento afetivo materno, o que, após tudo que já foi exposto, conferindo o fortalecimento intra-familiar, cuja expansão permitiria configurar uma rede social mais efetiva para uma melhor qualidade de vida para a mãe e o bebê $\hat{e}^{(5)}$.

Todos esses aspectos vêm sendo considerados pela equipe de saúde mediante a busca de estratégias para melhor oferecer assistência à saúde da mulher, bem como de todos os familiares envolvidos. Estudos que tratam de medidas preventivas dentro da Estratégia Saúde da Família favorecem essa dimensão do cuidado mais próximo da família, conferindo qualidade em todo o ciclo vital pela identificação precoce de doenças e eliminação de riscos ${ }^{(5)}$.

Diante da problemática apresentada surgiu a preocupação em pesquisar o tema deste estudo, que tem como objeto a percepção materna frente aos transtornos psiquiátricos puerperais. O estudo foi norteado pela seguinte questão: Quais as implicações dos transtornos psiquiátricos na relação mãe-filho, na percepção de mulheres que sofrem (ou sofreram) de transtornos psiquiátricos relacionados ao puerpério? O objetivo foi o de analisar as implicações dos transtornos psiquiátricos na relação mãe-filho na percepção da mulher em puerpério.

\section{PROCEDIMENTOS METODOLÓGICOS}

Trata-se de uma pesquisa qualitativa, descritiva, escolhida por promover uma abordagem mais adequada à compreensão e descrição da percepção materna nos transtornos psiquiátricos do puerpério, baseando-se na premissa de que existe uma relação dinâmica entre o mundo objetivo e a subjetividade do sujeito. A pesquisa foi submetida ao Comitê de Ética e Pesquisa da Faculdade NOVAFAPI (processo CAAE n. 1862.0.000.043-08).

O cenário da pesquisa foi um hospital psiquiátrico, de Teresina, Piauí, escolhido por ser uma instituição psiquiátrica pública estadual e considerado o serviço de referência no Estado. O hospital é uma instituição de ensino com 160 leitos de internação integral pelo SUS (Sistema Único de Saúde), trinta leitos de semi-internação (Hospital-Dia) e doze apartamentos reservados a atendimentos particulares e conveniados. São realizados mensalmente de cinco a seis mil atendimentos ambulatoriais, cerca de seiscentos atendimentos de urgência e emergência e duzentas internações integrais, que ocorrem de forma contínua, podendo ser mensal ou bimestral com duração de aproximadamente um ano (em média).

Os sujeitos do estudo foram dez puérperas em acompanhamento ambulatorial no hospital no período de setembro de 2007 a setembro de 2008 selecionadas conforme histórico de transtornos psiquiátricos associados ao puerpério e denominadas respectivamente de M1 a M10. O termo de Consentimento Livre e Esclarecido foi assinado por todos os sujeitos estudados, em consonância com o disposto no Decreto $\mathrm{n}^{\circ}$ 93933 de 14 de janeiro de 1987 e na Resolução no 196/1966 do Conselho Nacional de Saúde, que dispõe sobre as Diretrizes e Normas Regulamentadoras de Pesquisa envolvendo Seres Humanos. Após a assinatura do Termo de Consentimento Livre e Esclarecido, os sujeitos foram entrevistados no período de julho a setembro de 2008, tendo suas falas gravadas e transcritas com a máxima fidedignidade.

Após as transcrições dos depoimentos dos sujeitos, os dados foram analisados pela técnica de análise de conteúdo, realizando-se a análise temática das entrevistas e construindo-se três categorias. A primeira, intitulada $O$ desconhecimento da doença como fator de risco para o sofrimento psíquico, e a segunda, Interação mãe-filho, deram origem às seguintes subcategorias: o adoecimento e o prejuízo na relação materno-infantil; e o instinto maternal como fator de superação. A 
terceira categoria foi intitulada $\mathrm{O}$ impacto dos transtornos psiquiátricos puerperais no cotidiano das mães.

\section{RESULTADOS E DISCUSSÃO}

As doenças psiquiátricas do puerpério foram descritas na metade do século XIX pelo médico francês Louis Victor Marcé. Os efeitos da septicemia, trauma, dor, perda de sangue e exaustão contribuíam para incidência dos quadros psicóticos no pós-parto. Verificando a relação desse fenômeno com alterações fisiológicas da mulher e a alta prevalência de delirium, esse autor propôs que tais quadros teriam um caráter orgânico. A partir do século XX, a diminuição de infecções puerperais diminuiu a incidência de quadros confusionais psicorgânicos ${ }^{(7)}$.

A Síndrome da Tristeza Pós-Parto é descrita como uma síndrome leve e transitória que se inicia no terceiro ou no quarto dia após o parto, com tendência a atingir maior severidade entre o quinto e o décimo dia. A remissão dos sintomas ocorre espontaneamente e desaparece em, no máximo, duas semanas. Os sintomas são episódios frequentes de choro, flutuações do humor, tristeza, irritabilidade, fadiga, confusão, dificuldade de concentração, insônia e ansiedade, sendo esta, na maioria dos casos relacionada ao bebê $\hat{e}^{(3)}$.

Durante toda a gestação a mulher tem contato com mudanças significativas, de ordens físicas, hormonais e psíquicas, e o nascimento da criança materializa essas mudanças. Com o nascimento de um filho o meio circundante espera que a muIher esteja contente com o evento e seja 'uma boa mãe' (grifo nosso) não levando em conta, possíveis alterações na relação conjugal e familiar, ou na inserção social da mulher, que tem atividade ou carreira profissional interrompida ${ }^{(8)}$.

Nesse sentido, considerou-se pertinente caracterizar os sujeitos pesquisados quanto à idade, estado civil, antecedentes familiares, transtorno diagnosticado e número de gestações: 40\% com 15-20 anos; 40\% com 21-25 anos e 20\% com 26 anos ou mais; $50 \%$ eram casadas, $30 \%$ separadas e $20 \%$ solteiras; $100 \%$ das entrevistadas têm antecedentes psiquiátricos na família e $70 \%$ apresentaram transtorno de humor antes ou durante a gravidez; $80 \%$ das entrevistadas eram primíparas.

\section{O desconhecimento da doença como fator de risco para} o sofrimento psíquico.

A dificuldade das pacientes em se perceber doentes, devido a fatores culturais e sociais que agem frente aos fatores biológicos na definição de diagnóstico e tratamento dos transtornos, é condição prejudicial ao prognóstico.

Como eu não sabia dos sintomas não tinha nem como eu [...] é [...] saber da doença, reconhecer que eu tava doente. Por isso que eu acho que atrapalhou. (M9)

A maioria dos depoimentos indicou desconhecimento sobre os transtornos o que, para as entrevistadas, interferiu de forma significativa para o agravamento do quadro clínico. Isso porque, culturalmente, as mulheres tendem a buscar mais auxílio médico do que os homens, de modo que, se forem desenvolvidas estratégias de identificação de sintomas, as mesmas podem recorrer em busca de tratamento precoce.

Percebi quando eu senti que minhas forças não davam mais, que eu estava me sentindo assim, meu corpo já não dava mais para agüentar tanta coisa, mas eu não sabia que era depressão. (M1)

As depoentes sentiram-se doentes quando houve associação de sintomas típicos de depressão como alterações de humor, choro fácil, anedonia, tristeza profunda, pensamentos negativos e sentimentos de abandono e desesperança com quadros alucinatórios e ideação suicida. Pacientes mentalmente deprimidos costumam ter uma visão negativa do mundo e de si próprios. O conteúdo dos seus pensamentos por vezes inclui ruminações sobre perda, culpa, suicídio e morte ${ }^{(9)}$.

Percebi quando comecei ver coisas e sentir gente puxando meu cabelo, quando estava deitava na cama. (M10)

Desse modo, a pessoa não é mais capaz de sentir prazer em qualquer atividade e perde interesse pelas mesmas. Nesse sentido, uma depoente descreve que,

no momento da crise, você pensa que vai morrer, fica naquele desespero, naquela agonia. Uma coisa horrível demais. A vontade é de se livrar logo, de morrer ou não sei como é. (M5)

Por outro lado, os fatores sociais e culturais agravam os pedidos de "socorro" quando depressão esta associada aos estigmas da preguiça, conforme declara M4.

Porque é assim, quando a gente não tá dentro, a gente pensa que é bobagem, né? Quando vê uma pessoa dizer que tá deprimida, que não consegue pensar coisas boas, a gente pensa que é bobagem, frescura. Eu até já falei isso, que uma vizinha minha ela ficou com depressão, aí eu pensei: 'É frescura dela, é preguiça, é não sei o que'... Aí, quando a gente tá dentro é que a gente sabe como é... (M4)

Os dados mais significativos indicam que um episódio de psicose pós-parto é essencialmente uma manifestação de transtorno do humor, em geral de um transtorno bipolar ou, talvez, de um transtorno depressivo. O processo do parto pode ser visto como um estresse não específico que causa o desenvolvimento de um episódio de transtorno maior do humor, talvez devido ao mecanismo hormonal(4).

\section{Interação mãe-filho}

A interação mãe-filho fez emergir sentimentos conflitantes próprios do quadro das pacientes. Os transtornos mentais no pós-parto interferem não apenas na segurança da paciente, mas também na de seu bebê. As mães devem ser observadas em sua relação com os recém-nascidos: as ideias que expressam; como reagem ao contato e às demandas da criança. Mães deprimidas podem acreditar que o recém-nascido 
sofre de doenças ou malformações, podem se sentir culpadas por não sentirem amor pelo bebê, por não estarem cuidando dele. Uma mãe psicótica pode se encontrar sob uma influência delirante, e ver na criança algo anormal, diabólico. Deve-se, nesse caso, estar atento para o risco de infanticídio e de suicídio. A mãe pode, também, negar o nascimento da criança, não reconhecê-lo como filho. Uma avaliação formal da capacidade da mãe cuidar do bebê, para que se tornem as devidas medidas legais, pode ser necessária ${ }^{(3)}$.

Na subcategoria $O$ adoecimento e o prejuízo na relação materno-infantil foram abordados sentimentos culturalmente incomuns na relação mãe-filho e típicos de transtornos psíquicos puerperais. Assim desabafaram duas das depoentes:

Eu peguei meu filho com força e queria jogar ele no chão, só que, assim, antes de eu fazer isso minha irmã viu, chegou e pegou ele de mim [...] (choro) [...] Senão eu teria feito isso. (M7)

Acho que considero meu filho como o culpado por tudo que aconteceu. No término do meu relacionamento, já que o cara me largou quando soube que eu estava grávida [...] Sinto raiva do meu filho por isso. (M5)

A depressão materna no pós-parto é um dos fatores que provocam transtornos mais profundos na ligação mãe-bebê, prejudicando assim a interação. Quando a mãe não consegue oferecer respostas suficientes para atender as demandas e necessidades do seu bebê, ela pode experienciar reação de ansiedade, culpa, raiva, vergonha e autodepreciação, mostrando-se até mesmo hostil com seu bebê.

É uma coisa que não gosto nem de falar, mas, tinha hora que eu desejava que meu filho morresse [...] Ave Maria, depois que eu passei por isso foi que eu fui ver mesmo. Deus me livre. [...] Tinha hora que eu pensava assim: 'Meu Deus se meu filho morresse ia me livrar de tanto trabalho', essas coisas. (M2)

A depoente aponta a morte como uma solução para a falta de manejo e responsabilidade, além de um medo frente ao novo papel a ser desempenhado. O infanticídio e o suicídio estão entre as complicações mais graves decorrentes de transtornos puerperais sem intervenção adequada. No entanto, a existência de transtornos psiquiátricos não só no puerpério, mas também na gestação, pode levar a outras graves consequências ${ }^{(5)}$.

As mães podem, entretanto, apresentar mudanças de humor acentuadas e intermitentes em relação aos seus filhos, alterações estas que podem variar da extrema hostilidade, com rejeição, até extrema compensação dessa hostilidade, na forma de supersolicitude ao bebê $\hat{e}^{(10)}$.

Minha rejeição foi só na mente mesmo, mas de corpo assim não! Sempre cuidei dele. Eu tava com aquilo na minha mente, aquela agonia, chorava por cima dele e ele olhando para mim, e eu ficava 'ô meu Deus do céu tira essa coisa ruim de mim, essa agonia ruim'[...] Mas eu nunca deixei de dar assistência a ele não, nunca deixei de cuidar como tem que cuidar não. (M4)

Percebe-se que os sintomas descritos até o momento são clássicos e afetam a contingência da interação mãe-bebê. A labilidade de humor, o afeto prejudicado, o déficit de atenção, a hostilidade, além dos outros sentimentos experimentados pelas puérperas inibem a interação com o bebê. Essa defasagem de sentimentos leva algumas mães a uma espécie de prostração, ficando indiferentes ao bebê. Algumas não conseguem nem mesmo amamentar a criança.

Eu não amamentei. Eu não senti vontade de amamentar. Eu não queria ver ele logo que ele nasceu, achava que ele era o culpado de tudo, e [...] sentia raiva dele, assim, eu não [...] Não tive muita aproximação com ele logo que ele nasceu. Não tive uma relação verdadeira, relação de uma mãe com um filho [...] e agora não tem como voltar atrás. (M7)

O filho de mães que apresentam diagnóstico de depressão pós-parto tem dificuldades para dormir e se alimentar. Apresentam interação corporal com o ambiente e sorriso social diminuídos. As participantes deste estudo queixavam-se com muita freqüência de cansaço excessivo, o que acabava refletindo de forma negativa no relacionamento com seus filhos e, por consequência, no desenvolvimento deles. Deve-se, portanto, avaliar cada caso com especial atenção, a fim de estabelecer-se a melhor estratégia de tratamento para cada situação em particular, da maneira mais precoce possível ${ }^{(4)}$.

Pelo exposto percebe-se que o sentimento de culpa que atinge as mães que não podem ou não conseguem, de maneira satisfatória, responder as necessidades básicas dos seus filhos é agravado quando fatores culturais e sociais como ideal da maternidade é aproximado do cotidiano de mulheres que vivenciam esse sofrimento psíquico.

Na subcategoria Instinto maternal como fator de superação observou-se um contrapondo frente à hostilidade. Algumas depoentes demonstraram superação, projeção ou enfrentamento e o ideal de maternidade foi preservado. Utilizando-se do mecanismo de defesa projeção, uma delas afirma:

Não tentei nada contra meu filho, só contra meu marido. Na hora que eu tô em crise eu sempre olho pra ele (filho), assim, como se ele fosse a inspiração pra mim viver minha vida. (M1)

Eu pensava que tinha que me erguer por causa dele, assim como concorda dizendo num sei não, acho que pode ter sido até com ele (referindo ao pai da criança), mas com meus filhinhos não mudou nada não, porque, esta doido, uma vez meu filhinho adoeceu que eu faltei foi ficar louca... (M6)

Destaca-se, desse modo, a importância dos sentimentos da mãe em relação aos seus filhos. Na maternidade todas as mulheres, instintivamente, se tornam meigas, amorosas e dedicadas para com o seu bebê. $\mathrm{O}$ amor e a afeição pelo filho o tornam um objeto de contínuo interesse para a mãe, além de 
oferecer uma gama sempre renovada, rica e variada, todo um mundo de experiências vitais. Essa atitude emocionalmente centrada da mãe servirá para orientar os afetos e conferir uma qualidade de vida ao bebê(10). Essa superação e enfrentamento estão expressos na seguinte afirmativa:

Não, Deus me livre. As coisas ruins ficavam no meu pensamento, mas eu nunca [...] Nunca passou pela minha cabeça fazer alguma coisa com o meu menino. (M8)

Esse paradoxo é intrigante porque ao mesmo tempo em que a condição da maternidade abala os alicerces psíquicos da mulher a mesma maternidade pode servir como estratégia de enfrentamento por meio da sublimação revelando uma mãe, protegendo, acima de tudo seu bebê. É importante enfatizar que interação materna infantil satisfatória tem implicações fundamentais no desenvolvimento biopsicossocial da criança, como também, lembrar que uma boa relação mãe e filho não traz apenas conseqüências em longo prazo, mas principalmente diminui a possibilidade de maus tratos aos bebês e, em casos extremos, como no infanticídio.

\section{O impacto dos transtornos psiquiátricos puerperais no co- tidiano das mães.}

Os transtornos psiquiátricos puerperais trazem consigo uma gama de dificuldades inerentes a diversos aspectos da vida da portadora e da criança. Essas implicações podem vir como consequências da doença, mas também podem ser entendidas como fatores para a causa desta.

Com efeito, o nascimento de um filho altera a rotina da muIher alcançando uma perspectiva que ultrapassa o biológico pois, além de toda a responsabilidade que a sua nova condição impõe, ainda existe a necessidade de conciliar o filho com os demais papeis porventura desempenhados por ela.

Depois que eu tive ele (filho) as coisas pioraram. Veio a depressão que influi em varias coisas: não tenho como trabalhar, nem como me manter, nem manter o bebê. (M2)

O binômio da maternidade, da alegria de ser mãe versus esta responsabilidade, acarreta sentimentos conflituosos que, em associação com outros fatores desencadeantes, provoca na mulher estresse e ansiedade.

O meu filho tirou praticamente minha liberdade. Eu antes até estudava, mas agora tive que largar. (M5)

Existe dificuldade de integrar realização profissional, vida amorosa e maternidade, o que implica uma série de problemas de ordem prática, os quais muitas vezes resultam em sentimentos de culpa e inadequação. Além das preocupações relacionadas com as atividades profissionais e/ou estudantis, as preocupações de ordem financeira têm sido apontadas como estando associadas à depressão materna.

Se eu for escolher entre o trabalho e o menino, aí é que eu não vou ter tempo mesmo. Eu tentei ainda ir trabalhar no lugar do meu pai, que ele é cozinheiro, fui trabalhar [...] Aí num consegui, não consegui firmeza para trabalhar. (M6)

Além das dificuldades emocionais e econômicas encontradas para conciliar a maternidade com a vida profissional, percebe-se que os sintomas dos transtornos puerperais incapacitam na realização de tarefas, anteriormente consideradas de simples execução como limpar a casa, fazer uma comida, se alimentar ou até mesmo ter um padrão de sono e repouso satisfatório.

Está sendo muito difícil conviver com isso [...] Muito difícil. Eu não sinto vontade de fazer nada. Sem querer dormir, sem querer comer, sem vontade de fazer nada, nada em casa. (M8)

Observa-se que o puerpério é o período de maior risco para o aparecimento de um transtorno mental, se comparado com outros períodos da vida da mulher. Durante a gestação e o puerpério a mulher vivencia grandes modificações, tanto físicas como psíquicas e também em seu papel na família e na sociedade. Há alterações na autoimagem corporal, conflitos relativos à feminilidade, à sexualidade e à própria gravidez. Além disso, o parto pode ser vivenciado como perda (algo que fazia parte de seu corpo e foi retirado) e surgem sentimentos ambivalentes em relação à maternidade, ao novo bebê, ao marido e a si mesma ${ }^{(2)}$.

Não tinha paciência de fazer nada, nada, assim, varrer casa, fazer comida[...] Você é acostumada a ter um ritmo de vida e quando a criança nasce é totalmente diferente Eu sempre fui uma pessoa que gosta muito de organização, de limpeza, de tudo no seu lugar, aí depois que o menino nasceu não dava mais para mim conciliar ele com as coisas, aí ficava naquela confusão. (M3)

Enfim, o ciclo gestacional encerra um turbilhão de emoções que se manifestam fisicamente. A mulher com antecedentes familiares guarda predisposição biológica que, somada ao ideal de maternidade, ao contexto social e cultural, traz implicações consideráveis na relação mãe-filho, tornando as alterações próprias do ciclo reprodutivo uma porta de entrada para precipitação de transtornos psíquicos.

Nesse sentido a equipe de saúde, em especial os enfermeiros, que assistem as pacientes nas 24 horas do dia em âmbito hospitalar, deve atuar na prevenção e detecção precoce de sinais e sintomas, oferecendo apoio emocional e encaminhamento aos demais profissionais de saúde, desde o puerpério imediato, agindo assim na qualidade de vida de mulheres, crianças e famílias susceptíveis.

\section{CONCLUSÃO}

Os transtornos da gravidez, parto e puerpério são uma condição patológica complexa, que inclui desde quadros transitórios benignos, até situações graves que podem culminar em prejuízos irreparáveis para a mãe, a criança e família. A 
implicação dos transtornos psiquiátricos na relação mãe-filho revela graves conseqüências, pois a mãe deprimida não possui estabilidade emocional que possibilite uma maior interação com o seu filho.

Os fatores desencadeantes dos transtornos psiquiátricos no puerpério mencionados mostraram-se presentes nos sujeitos estudados, com particularidade para a história psiquiátrica familiar, detectada em 100\% das entrevistadas. Reflete-se, neste particular, a necessidade de um pré-natal que contemple não apenas o estado fisiológico e biológico da mãe, como também o seu aspecto psíquico, quando este e outros fatores podem ser precocemente identificados, aproximando a equipe de saúde da prevenção de transtornos psiquiátricos associados ao puerpério.
Assim, faz-se exeqüível que a equipe de saúde fortaleça a rede de apoio da mulher, favoreça o enfrentamento e, principalmente, esclareça à comunidade os sintomas de transtornos psiquiátricos de manifestação comuns durante o ciclo reprodutivo, a fim de estabelecer um diálogo entre o científico e senso comum, empoderando as mulheres.

Dar voz e vez à percepção das puérperas quanto aos transtornos psíquicos vivenciados no puerpério é passo importante para auxiliar práticas preventivas mais efetivas em ações da saúde executadas pelos diversos profissionais envolvidos na promoção de saúde, numa perspectiva ampliada da elaboração de programas diferenciados de políticas públicas de saúde, no âmbito da atenção básica, voltados para a comunidade feminina durante sua fase reprodutiva, especialmente no ciclo gravídico-puerperal.

\section{REFERÊNCIAS}

1. Tuono VL, Mello Jorge MHP, Gotlieb SLD, Laurenti R. Transtornos mentais e comportamentais nas mortes de mulheres em idade fértil. Epidemiologia e Serviços de Saúde 2007; 16(2); 85-92.

2. Zanotti DV, Saito KC, Rodrigues MD, Otani MAP. Identificação e intervenção no transtorno psiquiátrico e intervenção no transtorno, associadas ao puerpério: A colaboração do enfermeiro psiquiatra. Rev Nursing 2003; 61(6); 36-42.

3. Ramos SHAS, Furyado EF. Depressão puerperal e interação mãe-bebê: um estudo piloto. Psicologia em pesquisa 2007; 1(1): 20-28.

4. Camacho R.S. et al. Transtornos psiquiátricos na gestação e puerpério: classificação, diagnóstico e tratamento. Rev. Psiqui Clin 2007; 23(2): 92 - 99.

5. Simoni AS, Geib LTC. Percepção materna quanto ao apoio social recebido no cuidado às crianças prematuras no domicílio. Rev. bras. enferm. 2008; 61(5): 545-551.

6. Ximenes Neto FRG, Cunha ICKO. Integralidade na assistência à mulher na prevenção do câncer cérvico-uterino: um estudo de caso. Texto contexto - enferm Set 2006: 15(3): 427-433.

7. Botega NJ. Prática Psiquiátrica no Hospital Geral: interconsulta e emergência. Porto Alegre: Artemed; 1999.

8. Luís MAV, Oliveira ER. Transtornos mentais na gravidez, parto e puerpério na região de Ribeirão Preto- SP- Brasil. Rev. Lat Ame Enf. 1998 v.32, n.4, p.314-324.

9. Sadock BJ, Sadock VA. Compêndio de psiquiatria: ciências do comportamento e psiquiatria clinica. Porto Alegre: Artmed; 2007.

10. Spitz RA. O primeiro ano de vida. São Paulo: Martins Fortes; 2000. 